\title{
INFLUENCE OF THE WAVE REGIME IN COASTAL SEDIMENT BUDGET: PRESENT AND FUTURE SCENARIOS
}

\author{
Sandra Plecha ${ }^{1}$, Carina L. Lopes ${ }^{1}$, Nicolas Bruneau², Nuno A. Ribeiro ${ }^{3}$, Paulo A. Silva ${ }^{4}$, André \\ B. Fortunato ${ }^{3}$ and João M. Dias ${ }^{1}$
}

\begin{abstract}
The wave regime has a strong influence on the sediment transport in coastal systems. Modifications in wave regime induced by climate changes can influence the sediment dynamics of those coastal systems. To access wave regime changes it is crucial to analyse the future modifications in the wave height, period and direction. This work aims to analyse the influence of a future wave regime in the sediment budget of a coastal lagoon inlet and at the nearshore adjacent coast. To achieve this goal a morphodynamic modelling system was used, forced by present and future waves, corresponding to a typical year of present and future wave climates. A methodology to determine a typical year of each climate was developed based on the determination of correlation coefficients between each climate and corresponding year data. The comparison between present and future wave climates evidences that wave period and height are in general similar for both climates, and confirms the anticlockwise rotation of waves in the future. The morphodynamic simulations revealed analogous results for both wave climates, resulting in similar patterns for the residual sediment fluxes, but slightly more intense in the present. The consequent bathymetric changes show that the deposition trend presently observed offshore the inlet tends to increase for future waves climate. The transport budgets were also analysed for both wave regimes, evidencing that the alongshore transport slightly decreases ( 1\%) for future waves.

Keywords: wave climate; climate change; morphodynamics; Ria de Aveiro
\end{abstract}

\section{INTRODUCTION}

The alongshore sediment transport driven by the impinging oblique waves is the result of a complex pattern of sediment fluxes and long-shore currents that eventually leads to a net sediment erosion or accretion at the shorelines. Modifications in the coastal sediment budget associated, for example, to scarce sediment resources and modifications in the physical agents (e.g. wave climate, mean sea level) can promote over time morphologic changes at the shoreline and at the inlets located nearby. These changes might influence the stability of the man-made structures, the navigation in the channels, and the ecological habitat.

The climate changes evidence modifications in the wind patterns that will result in alterations in extreme wave events and wave directions affecting coastal systems, such as the dynamics of the tidal inlets (Bruneau et al., 2011). Previous studies showed that in the Portuguese coast the wave climate will be modified in the future as a result of climate change. Andrade at al. (2006) applied the wave model MAR3G to the Atlantic and found for the Portuguese coast only minor changes in the wave significant height and a clockwise rotation of $5^{\circ}$ to $15^{\circ}$ in the future wave climate direction, with respect to the present. They also studied the impacts of this rotation on the littoral drift. The results show that the clockwise rotation will enhance coastal erosion by 15 to $25 \%$.

Recently, Dodet et al. (2010) analysed past trends in time series of wave parameters in the NorthEast Atlantic Ocean for the period 1953 to 2009. They found a negligible increase in significant wave height ( $\sim 0.002 \mathrm{~m} /$ year) and a clockwise rotation of the winter waves of about $0.05 \%$ year and of summer waves of $0.002^{\circ} /$ year.

These changes reported for the wave regime motivate the prediction of the present and future (SRES A2) wave climate for the Portuguese coast in the frame of this the study, applying the WaveWatchIII model forced by ECHAM5/MPI-OM wind data.

The main aim of this work consists in the analyses of the coastal sediment budget at the nearshore of the Ria de Aveiro lagoon inlet, located at the northwest of the Iberian Peninsula, for the present and future wave climates. The 2DH morphodynamic modeling system MORSYS2D (Fortunato and Oliveira, 2004, 2007; Bertin et al., 2009) was considered in order to evaluate the changes in sediment transport induced by changes in the wave regime. The present and the future wave climate forcing in the simulations are imposed as time series of wave spectra resulting from the WaveWatchIII predictions. Due to computational limitations and considering that the errors in morphodynamic simulations tend to increase for long term simulations (Fortunato et al., 2009), the present work

\footnotetext{
${ }^{1}$ NMEC and CESAM, Physics Department, University of Aveiro, Campus de Santiago, Aveiro, 3810-193, Portugal

${ }^{2}$ British Antarctic Survey, High Cross, Madingley Road, Cambridge, CB3 OET, United Kingdom

${ }^{3}$ Estuaries and Coastal Zones Division, National Laboratory for Civil Engineering, Av. Brasil 101, Lisboa, 1700-066, Portugal

${ }^{4}$ CESAM, Physics Department, University of Aveiro, Campus de Santiago, Aveiro, 3810-193, Portugal
} 
presents one year simulations instead of 30 years (corresponding to each climate). A methodology to determine a typical year of each climate was developed based on the determination of correlation coefficients between each climate and corresponding year data.

\section{STUDY AREA}

The coastal zone studied is a section of the Portuguese west coast, located in the northwest of the Iberian Peninsula that encompasses a shallow mesotidal lagoon (Ria de Aveiro) with a stabilized artificial inlet. The Ria de Aveiro (Figure 1) is a shallow vertically homogeneous lagoon $45 \mathrm{~km}$ long and $10 \mathrm{~km}$ wide which covers an area of $83 \mathrm{~km}^{2}\left(66 \mathrm{~km}^{2}\right)$ at high (low) water spring tide (Dias and Lopes, 2006). It is characterised by narrow channels and by large areas of mud flats and salt marshes. Its main channels are Mira, S. Jacinto, Ílhavo and Espinheiro. The Espinheiro channel receives the main input of fresh water in the lagoon by the Vouga River. This input represents about 2/3 of the total fresh water flow into the lagoon (Dias, 2001).



Figure 1. a) Location and b) numerical bathymetry of the study area.

The inlet region provides access to the Aveiro harbour. The average depth in the navigation channel (13 m relative to chart datum) is greater than the average depth of the remaining lagoon (1 m relative to chart datum).

Human action has been the major factor controlling the lagoon morphology (Silva and Duck, 2001). The most noteworthy human intervention was the creation of the artificial inlet in 1808, in response to the persistent accretion of the natural inlet. In the following years, several works were performed in order to improve the access to the Aveiro harbour, namely the construction of two breakwaters in the first half of the $20^{\text {th }}$ century, whose extension grew until the last intervention between 1983 and 1987. The extension of the Northern breakwater together with the regular channel dredging led to a deepening of the channels in the inlet region (Plecha et al., 2007). The northern breakwater extension has also affected the alongshore littoral drift, leading to sediments accumulation (erosion) north (south) of the inlet (Plecha et al., 2007).

The lagoon adjacent region is subjected to a highly energetic wave climate with a yearly mean significant wave height (Hs) of 2-2.5 m, wave periods of 9-11 s corresponding to WNW to NNW swell (Andrade et al., 2002). As a consequence of this wave climate there is a strong southward littoral drift of $1 \times 10^{6} \mathrm{~m}^{3} /$ year (Larangeiro and Oliveira, 2003). This strong littoral drift together with the natural tendency of the lagoon to export sediments led to a submerged sandbank formation offshore of the inlet (Plecha, 2011). 


\section{MORSYS2D MODEL}

The 2DH morphodynamic modeling system MORSYS2D (Fortunato and Oliveira, 2004, 2007; Bertin et al., 2009), schematized in Figure 2, was used to simulate the sediment dynamics and the morphological evolution of the study area. This modeling system integrates the hydrodynamic model ELCIRC, which calculates tidal elevations and currents, the wave model SWAN, which computes wave propagation and the model SAND2D that computes sand transports and updates the bottom topography.

ELCIRC is an open-source model developed for the simulation of 3D baroclinic circulation that uses a finite-volume/finite-difference Eulerian-Lagrangian algorithm to solve a set of six hydrostatic equations based on the Boussinesq approximations: mass conservation, momentum conservation and conservation of salt and heat (Zhang et al., 2004). Within MORSYS2D, the hydrodynamic model Elcirc is used in 2D mode.

The spectral wave model SWAN solves the wave action density balance equation (Booij et al., 1999) and was used in MORSYS2D to simulate wave propagation from the open sea up to the shoreline. SWAN is fed by outputs of velocities and elevations from the hydrodynamic model (ELCIRC) linearly interpolated over regular grids. SWAN can be forced at its open boundary by constant wave parameters, time series of mean wave parameters (WaveWatchIII model (Tolman et al., 2002)), by wave spectra originating from the WaveWatchIII model or from oceanic wave buoy observations. Significant wave height, period, direction, wavelength, and orbital velocity are outputted from SWAN every $1800 \mathrm{~s}$, and used to compute gradients of radiation stresses to force the hydrodynamic model (ELCIRC) and to compute sand fluxes into SAND2D.

SAND2D developed by Fortunato and Oliveira (2004, 2007) and Bertin et al. (2009) computes the sand transport and the bottom update. The sand fluxes due to the effect of tidal currents and waves forcing are simulated by using one of the several formulations implemented. The numerical simulations presented herein used the Ackers and White (1973) (AW) formulation for tidal currents, adapted by van de Graaff and van Overeem (1979) to take into account the waves effect. The stability of the numerical model is ensured by an adaptative morphodynamic time-stepping procedure, previously tested in a very dynamic tidal inlet (Bertin et al., 2009).

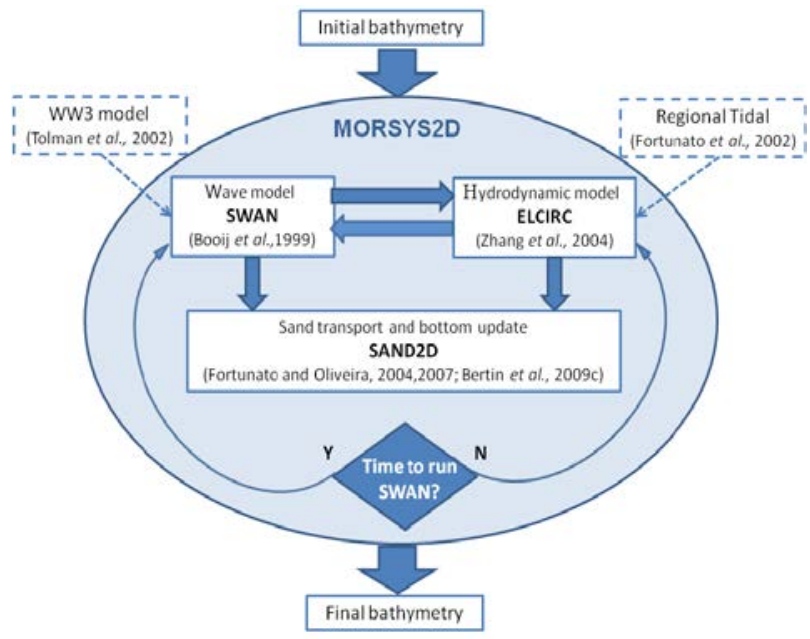

Figure 2. Schematic diagram of the MORSYS2D morphodynamic model system.

The MORSYS2D modeling system was previously calibrated and validated to the Ria de Aveiro lagoon and successfully applied to study the morphodynamic changes at its inlet (Plecha, 2011, Plecha et al, 2007, 2010, 2012, Lopes et al, 2011). The bathymetric trends computed through numerical simulations were compared with surveys performed by the Administration of the Ria de Aveiro Harbour, and was concluded that, according to the Brier Skill Score classification (Sutherland et al. 2004), the numerical model provides good predictions (Plecha et al., 2012).

\section{METHODOLOGY}

The methodology followed in this work is schematically represented in the Figure 3. The wind data outputted by climate model ECHAM5/MPI-OM (Roeckner et al., 2003; Marsland et al., 2003) were used to force the wave model WW3 previously implemented for the North East Atlantic Ocean by 
Dodet et al. (2010). The wind data used have been made available to the scientific community by the World Climate Research Programme's (WCRP's) Coupled Model Intercomparison Project phase 3 (CMIP3) multi-model dataset (Meehl et al., 2007). The present (1971-2000) and future (2071-2100) wind data correspond to 20C3M and SRES scenario A2 simulations, respectively. The 20C3M and A2 scenarios were described in the IPCC (2007) report. The application and calibration of WW3 forced by the climate model is described in Ribeiro et al. (2012).



Figure 3. Flowchart of methodology followed in the work.

The results of WW3 at a point close to the Ria de Aveiro inlet were considered in order to characterize the present and the future wave climates. In turn the present and the future wave climates were statistically analysed in order to determine one year of wave data which is representative of each climate. The annual wave data time series of the year considered representative of each climate were used to force the morphodynamic model MORSYS2D.

The influence of the present and future wave regimes in the coastal sediment budget is analysed by comparing the residual sediment fluxes and bathymetric changes predicted through numerical simulations. The residual fluxes are obtained by averaging the results of 60 days simulations (starting on January $\left.1^{\text {st }}\right)$ during two MSf (lunisolar synodic fortnightly) constituent periods $(2 \times 14.78$ days). These residual fluxes are computed and analysed at the entire study area and at five cross-sections (Figure 4), defined to encompass the nearshore region. The bathymetric changes and sediment budget, due to computational limitations, were performed for a 1 year period, instead of 30 years, allowing the evaluation of bathymetric changes and sediment budgets for each wave climate.

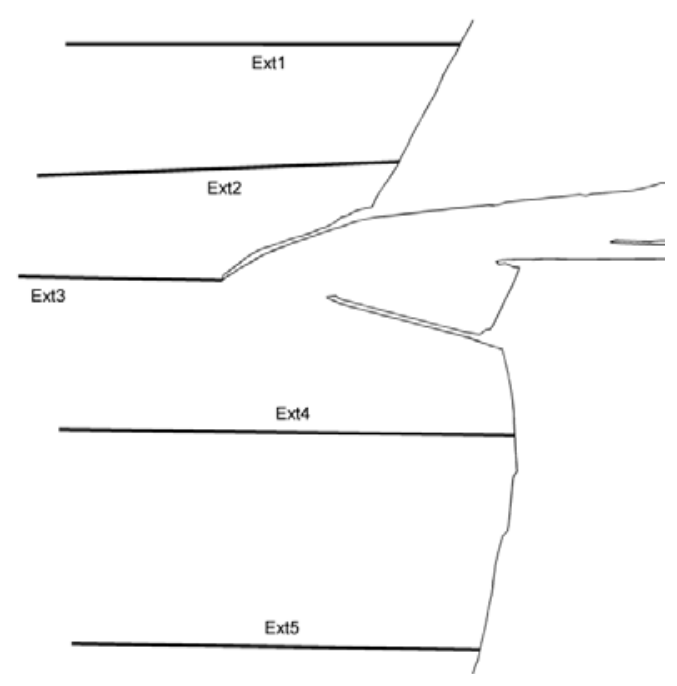

Figure 4. Sections location where transport of sediments is computed (Ext1 to Ext5). The sections were defined in order to be coincident with variations in the lagoon inlet bathymetry or geometry. 


\section{RESULTS}

First, a statistical analysis of each wave climate was made to determine the year representing the typical climate. The analysis compares the 30 years data of each climate with each year data of the respective climate. In this frame the period $(T)$, the wave height $\left(H_{s}\right)$ and the direction (Dir) were grouped in classes and the percentage of occurrence was determined for the 30 years data and for each year. The next step was the computation of the correlation coefficient between each year and the respective climate for each parameter. The results obtained for each climate are presented in Figure 5. The correlation coefficients are higher than 0.84, revealing a good correlation between a single year and the respective climate. However, the three wave parameters should be compared simultaneously in order to determine the year representative of the typical wave climate. Considering that the perfect adjustment between a year and the respective climate matches a correlation coefficient of 1 for the three parameters, the deviation $(d)$ between each year and the perfect adjustment was computed as:

$$
d=\sqrt{\left(1-c_{H s}\right)^{2}+\left(1-c_{T}\right)^{2}+\left(1-c_{D i r}\right)^{2}}
$$

where $c_{H s}, c_{T}$ and $c_{D i r}$ are the correlation coefficients of wave height, wave period and wave direction, respectively. The deviation values for each climate are presented in the Figure 6. The years 1977 and 2084 are the ones that present the smaller deviations, 0.01 and 0.008 respectively, being considered representatives of each climate.

a)

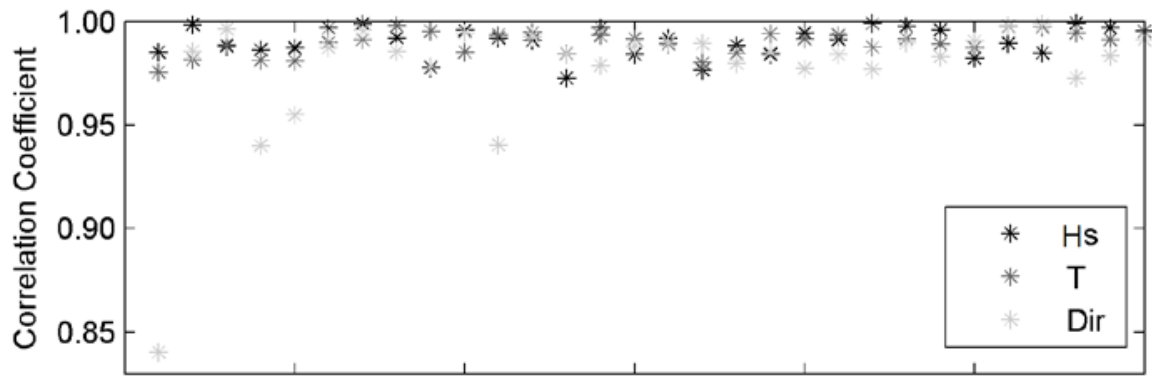

b)

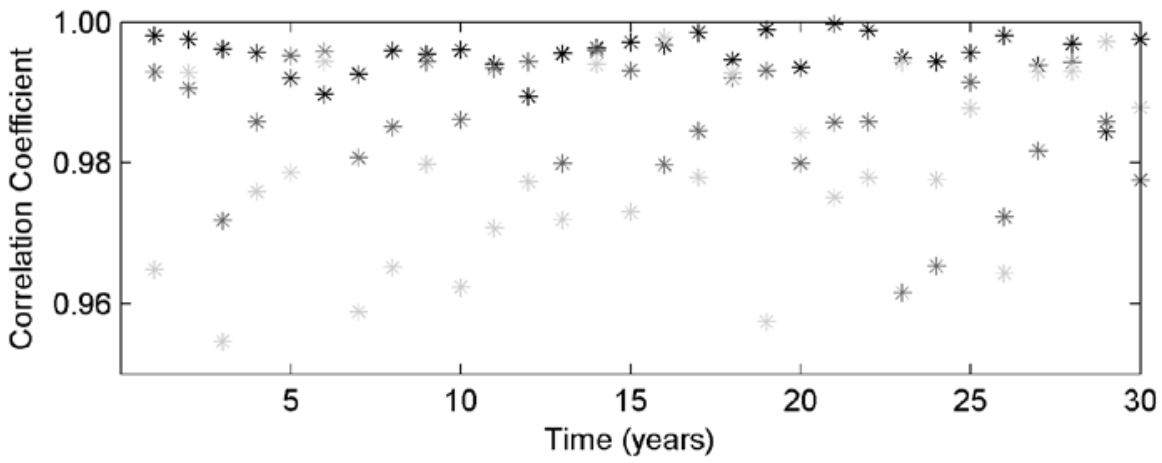

Figure 5. Correlation coefficient of wave height $\left(H_{s}\right)$, wave period $(T)$ and wave direction (Dir) between each year and 30 years for: a) Present climate; b) Future climate.

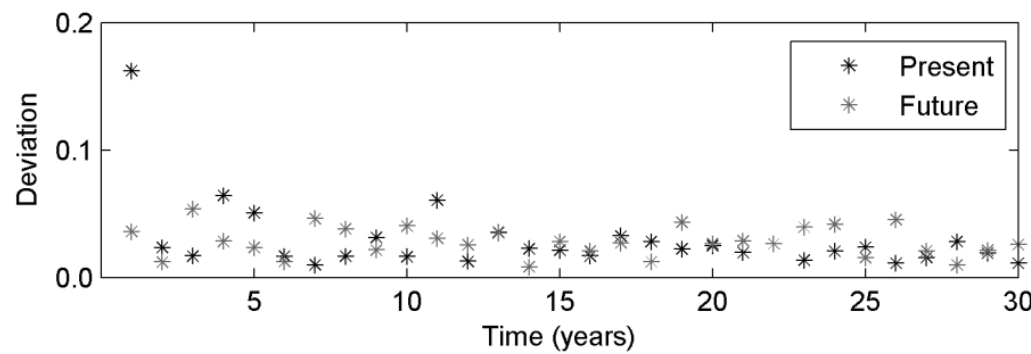

Figure 6. Deviation between each year and the perfect adjustment for present and future climates. 
For both selected years, the percentage of occurrence of wave direction, significant height and period were grouped in classes (see Figure 7). Both significant height and period are very similar for present and future climates; however significant changes are found in the wave direction. The evidence of more waves with westward component in the future wave climate than in the present indicates an anticlockwise rotation.

a)

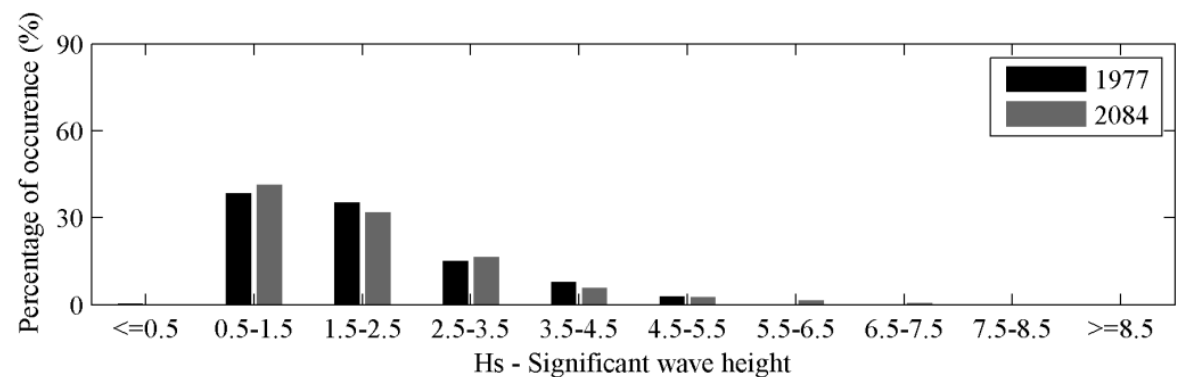

b)

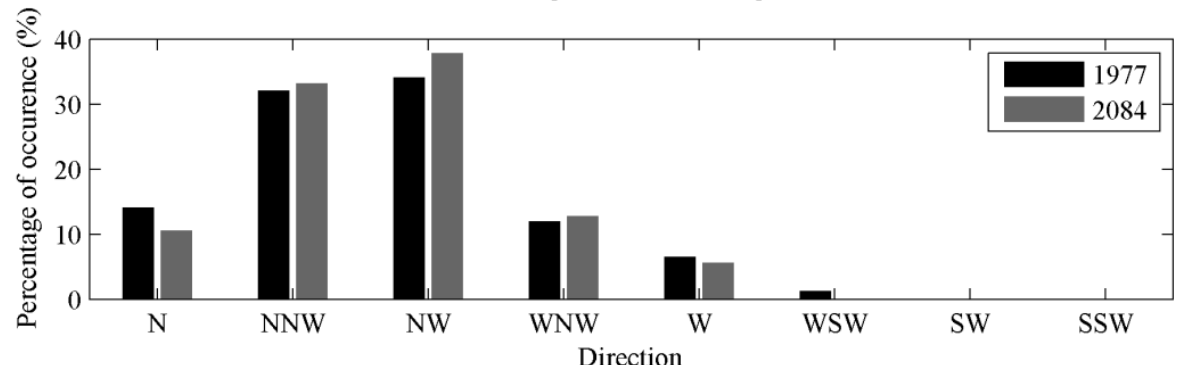

c)

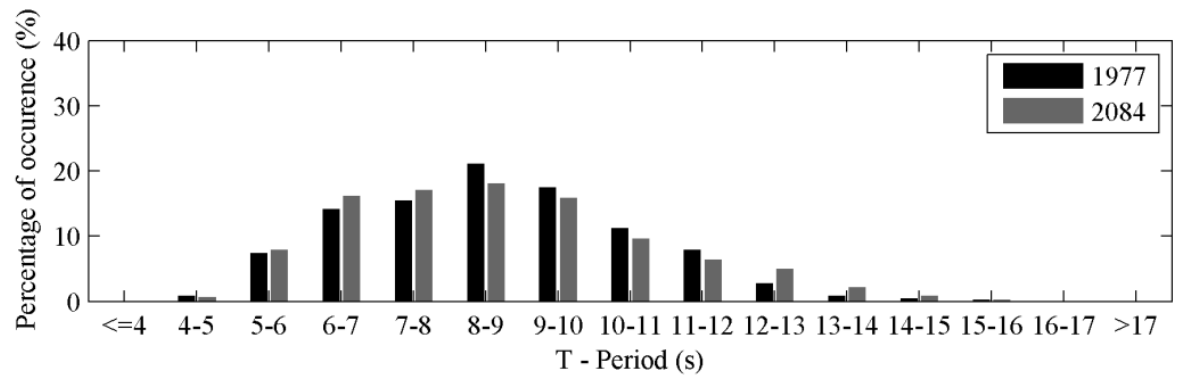

Figure 7. Annual distributions (\%) of: a) significant wave height; b) wave direction; c) wave period.

The time series of the selected representative years were used to force the morphodynamic model MORSYS2D. Details of wave height and direction inputted in MORSYS2D model are presented in Figure 8. This figure evidences higher percentage of NE/small significant wave height for the present climate and higher percentage of NW/high significant wave height for the future climate.

a)

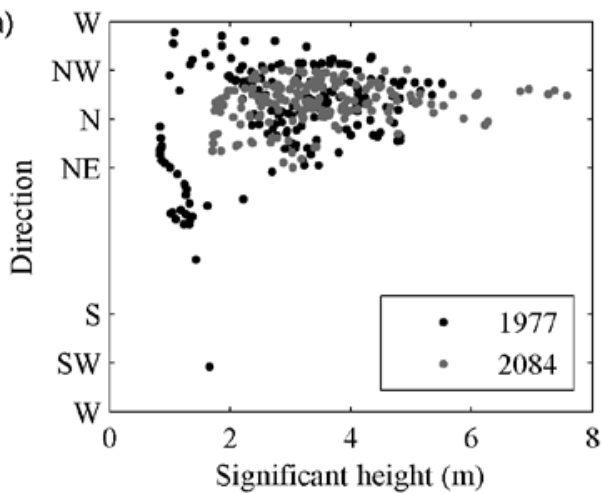

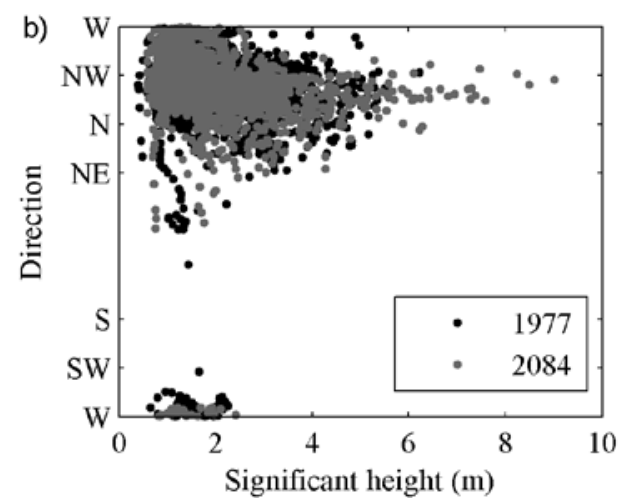

Figure 8. Wave direction in function of significant wave height: a) 60 days runs; b) one year runs. 
The residual sediment fluxes were computed for each wave climate (Figure 9) to evaluate the consequences of the changes found in the wave climates in the lagoon adjacent coast morphodynamics. The results evidence that the flux pattern is similar for both simulations, directed outward, which denotes the ebb-dominance of the coastal system. At the nearshore areas the residual fluxes are predominantly directed north-south, induced by the longshore currents generated by the wave regime typical of the study area. The presence of a re-circulation pattern is evident southward of the inlet. The analysis of the flux intensity differences induced by the future wave regime (Figure10) shows a reduction of fluxes magnitude, mainly offshore the inlet.

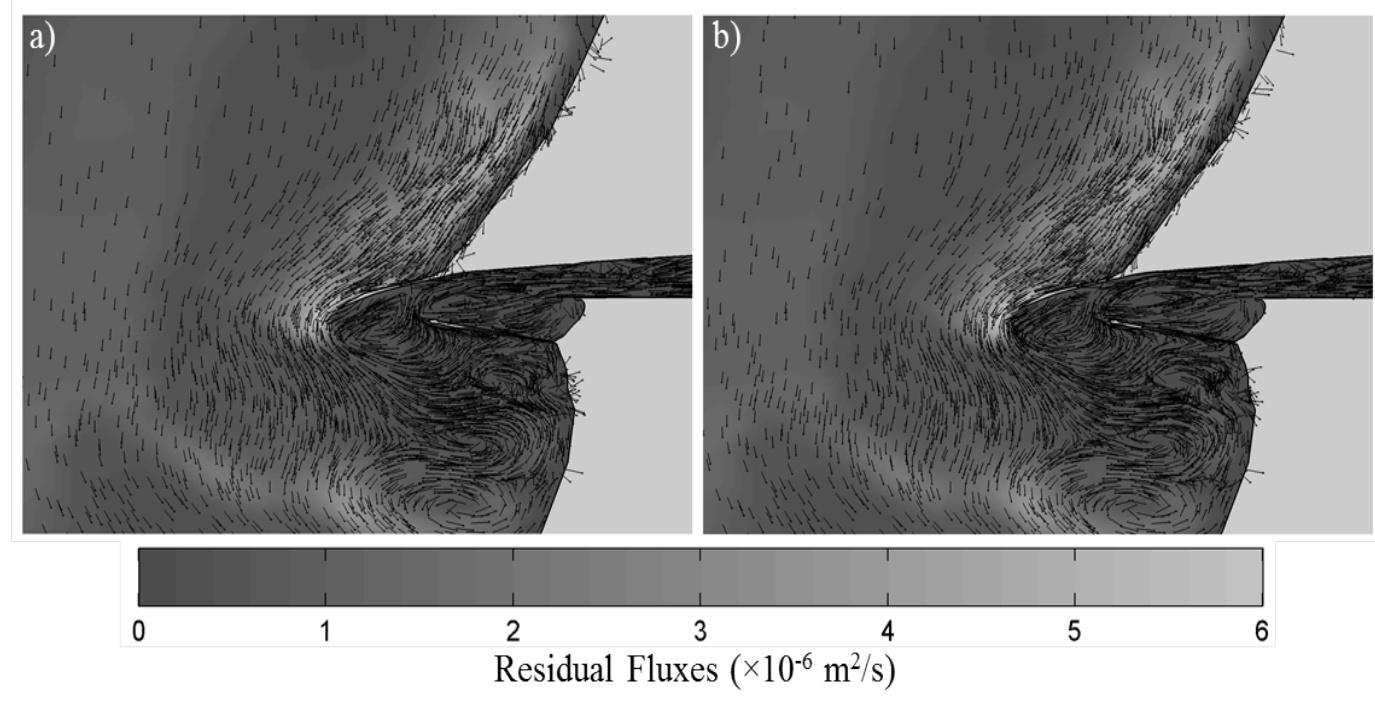

Figure 9. Residual sediment flux $\left(\mathrm{m}^{2} / \mathrm{s}\right)$ for simulations considering the a) present and b) future wave climate.

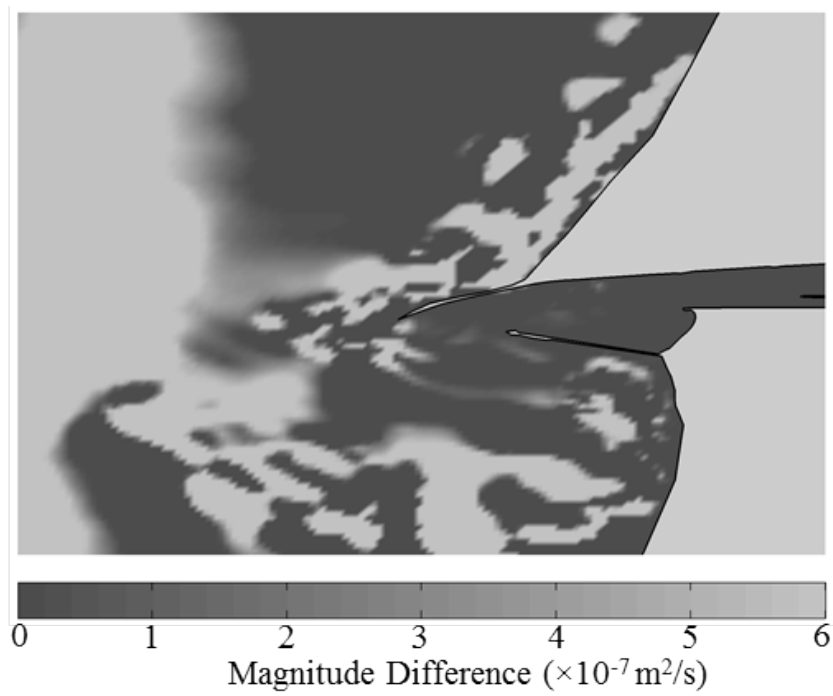

Figure 10. Difference between present and future residual flux intensity.

The analysis of the residual sediment fluxes at the five sections shown in Figure 4 shows that the present and future wave climates generate similar fluxes for all the sections. Therefore, only the residual fluxes induced by the present wave regime are represented (Figure 11). The fluxes are related to the drift currents generated by the breaking waves.

The higher fluxes occur at the section located close to the north breakwater, where the influence of this structure is experienced. The "uniformity" observed northward of the inlet is not found at the southward sections where re-circulations are observed, induced by the breakwaters that define the artificial inlet and by the existence of local submerged sandbanks. 

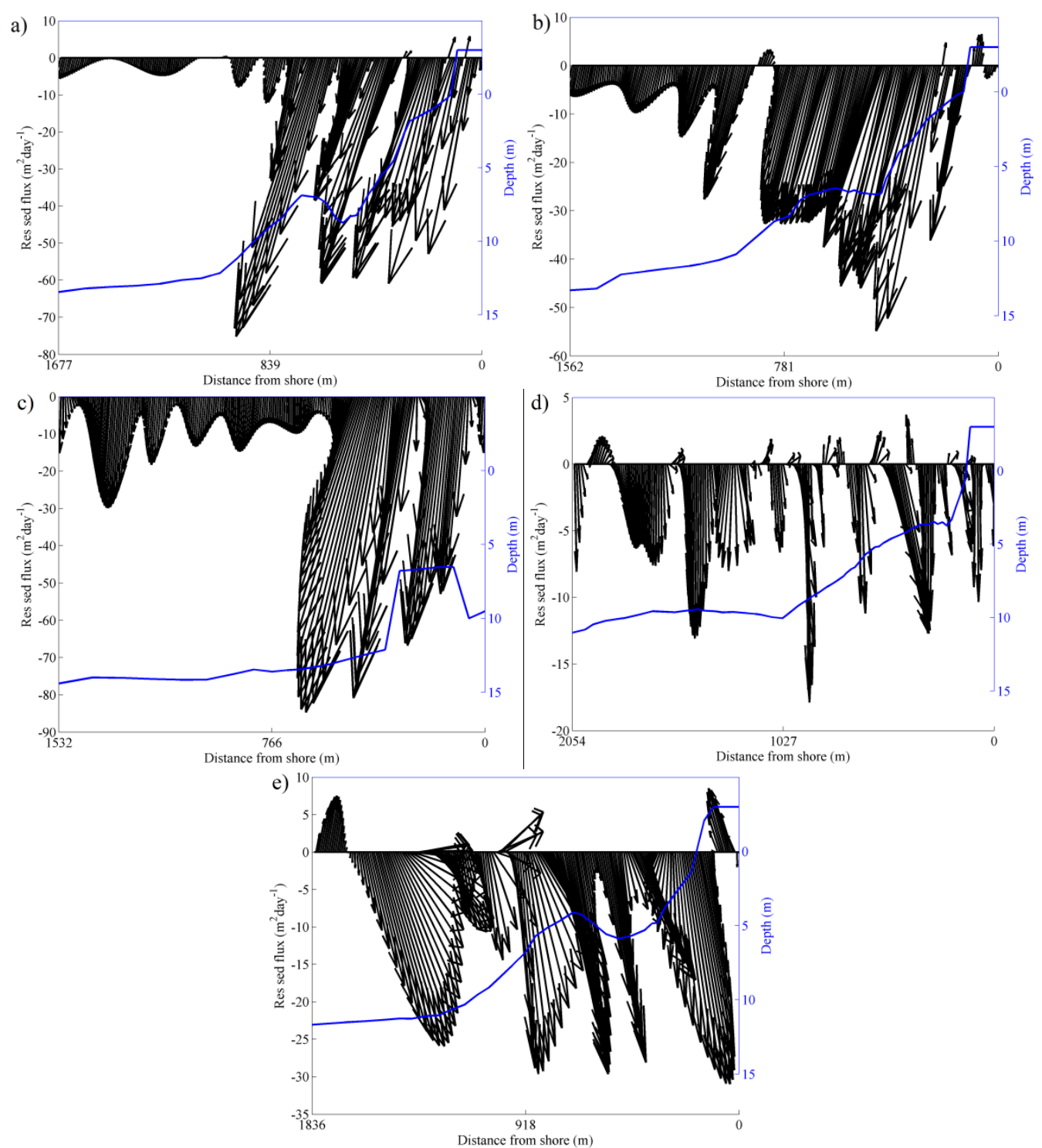

Figure 11. Residual sediment flux ( $\mathrm{m}^{2} /$ day) for the sections located at the offshore area of the inlet $\left.\mathrm{a}\right)$ Ext1, b) Ext2, c) Ext3, d) Ext4 and e) Ext5, for simulations considering the present wave climate. The section depth is illustrated by the solid line and by the right axis of the subfigures.

An evaluation of the annual alongshore transport at sections Ext1-3 was performed and is presented in Table 1. Comparing these values with those presented in the literature (e.g., Oliveira et al. (1982) evaluated the littoral drift at the range of $1-3.5 \times 10^{6} \mathrm{~m}^{3}$ year ${ }^{-1}$, Teixeira (1994) proposed the range 1.4-1.7 $\times 10^{6} \mathrm{~m}^{3}$ year ${ }^{-1}$, Andrade et al. (2002) proposed the range $1-2 \times 10^{6} \mathrm{~m}^{3} \mathrm{year}^{-1}$, Larangeiro and Oliveira (2003) proposed $1 \times 10^{6} \mathrm{~m}^{3}$ year ${ }^{-1}$ and Coelho (2005) the value of $1.1 \times 10^{6} \mathrm{~m}^{3}$ year ${ }^{-1}$ ), were found higher estimated values in the present study. The over-estimation of present results can be justified by the winter wave regime period considered in the numerical simulations for the estimation of the sediment fluxes, which are extrapolated to estimate the annual alongshore transport. The comparison between the estimations for present and future wave regimes shows that the changes in the alongshore transport are only approximately $1 \%$ and therefore may be considered negligible.

\begin{tabular}{|l|c|c|}
\hline \multicolumn{3}{|c|}{ Table 1. Annual alongshore transport $\left(\times \mathbf{1 0}^{6} \mathbf{~}^{3}\right.$ year $\left.^{-1}\right)$} \\
\hline & Present & Future \\
\hline Ext1 & 5.99 & 5.97 \\
Ext2 & 6.33 & 6.29 \\
Ext3 & 4.32 & 4.35 \\
\hline
\end{tabular}


The bathymetric changes induced by the sediment transport fluxes presented above for a 1 year simulation are illustrated in Figure 12, for both wave regimes. As consequence of the similar transport, also the bathymetric changes obtained for both simulations are very similar. Nevertheless, higher bathymetric changes are found at the mouth and at the offshore adjacent area of the lagoon inlet. For both simulations, the wave climate effects push the sediments towards the inlet, resulting in the accretion trend predicted outside the inlet. This is a consequence of the convergence of the local northsouth littoral drift induced by the wave climate (see Figure 9).

Near the northern breakwater head the predictions for both regimes reveal a strong erosion trend originated from the north-south sediment fluxes at the head of this structure, as illustrated in Figure 9. Close to the offshore side of the south breakwater head, an erosion trend is also predicted, induced by the coupling between residual fluxes originated by the littoral currents and the ebb dominance of the lagoon.

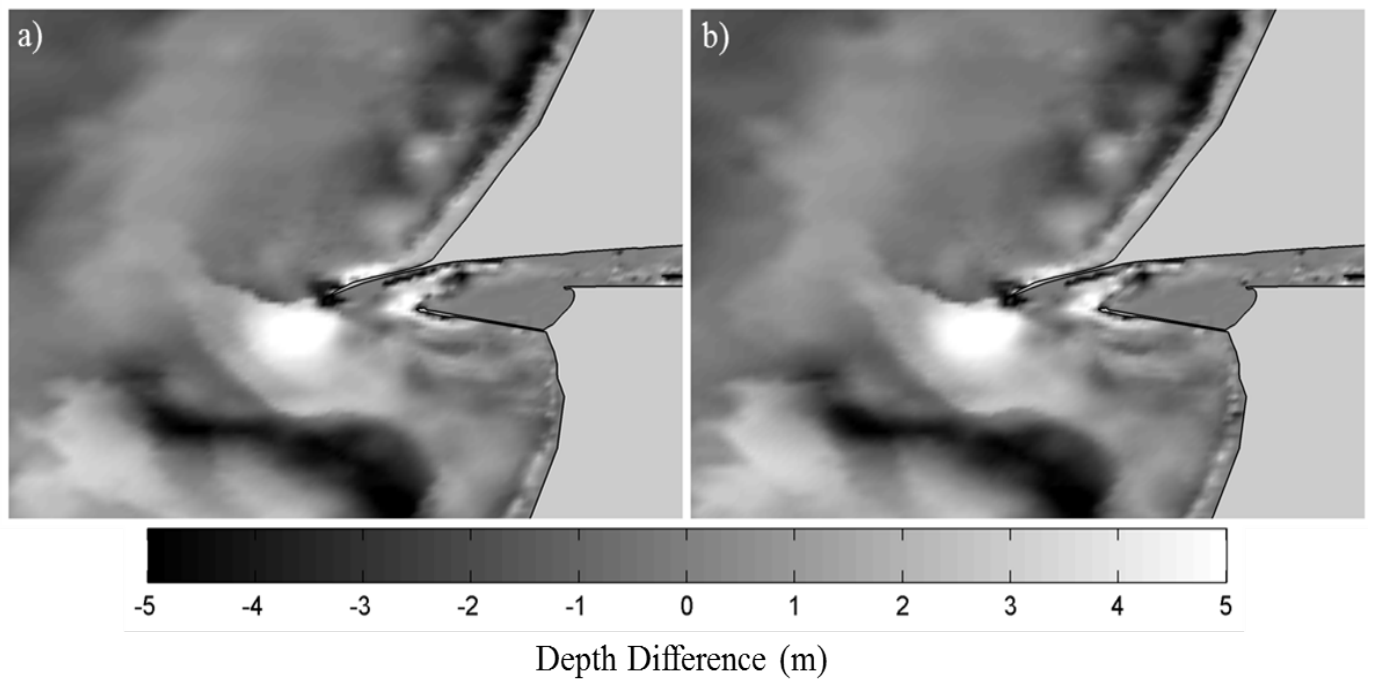

Figure 12. Difference between the computed final and initial bathymetries (meters) for a 1 year simulation considering the a) present and b) future wave regimes. Negative (positive) values represent erosion (accretion).

Despite the differences in the imposed wave regime characteristics (Figures 7 and 8), the magnitude of the changes in the depth between the present and future bathymetries predicted for a 1 year simulation is not significant, as illustrated in Figure 13. Nevertheless, it can be observed that the accretion trend offshore the inlet tends to increase. 




Figure 13. Depth difference between simulated bathymetries (Present - Future).

\section{CONCLUSIONS}

The present and the future (SRES A2) wave climates offshore Ria de Aveiro were determined from WW3 forced by ECHAM5/MPI-OM wind data. A methodology was developed to determine the best year representative of the local wave climate for each period. From this analysis the years 1977 and 2084 were considered typical of present and future climates.

The present and future wave regimes analysed are composed by waves with similar periods and significant wave heights, but were found changes in the wave direction, being observed an anticlockwise rotation of future waves: changes in the wave direction (an anticlockwise rotation) was found in the future wave climate.

Both wave regimes imposed generate similar residual sediment fluxes, directed from North to South, northward the inlet. At the south side of the inlet re-circulations are observed, evidenced by the interaction of waves with breakwaters and submerged sandbanks. Computing the alongshore transport, a slight decrease of alongshore transport for future waves is observed ( 1\%).

Consequently, the bathymetric changes predicted by the numerical simulations are similar for both regimes, consisting in accretion outside the inlet, in strong erosion near the head of the north breakwater and also erosion close to the offshore side of the south breakwater head. Despite these similarities, the deposition trend observed offshore the inlet tends to increase for future wave regime.

\section{ACKNOWLEDGMENTS}

Carina L. Lopes has been supported by FCT through a PhD grant SFRH/BD/78345/2011. This work has been partly supported by FCT and by European Union (COMPETE, QREN, FEDER) in the frame of the research projects: AdaptaRia (PTDC/AAC-CLI/100953/2008) and DyEPlume (PTDC/MAR/107939/2008). The authors would like to thank Profs. A.M. Baptista and Joseph Zhang for the model ELCIRC (www.stccmop.org/CORIE/modeling/elcirc/index.html), the Aveiro Harbor Administration for providing the bathymetric data and the people involved in the EMERA project, in particular, Maria Virginia Martins, for the sediment characteristics. The authors would like also to thank to Xavier Bertin from Université de La Rochelle, for the help provided in the implementation of MORSYS2D to the Ria de Aveiro lagoon and to Prof. Alfredo Rocha from University of Aveiro for providing the wind database.

The authors acknowledge the modeling groups, the Program for Climate Model Diagnosis and Intercomparison (PCMDI) and the WCRP's Working Group on Coupled Modelling (WGCM) for their roles in making available the WCRP CMIP3 multi-model dataset. Support of this dataset is provided by the Office of Science, U.S. Department of Energy.

\section{REFERENCES}

Ackers, P. and W.R. White. 1973. Sediment transport: a new approach and analysis. Journal of Hydraulic Division, 99, 2041-2060. 
Andrade, C., M.C. Freitas, C. Cachado, A.C. Cardoso, J.H. Monteiro, P. Brito, and L. Rebelo. 2002. Coastal Zones. In: Santos FD, Forbes K, Moita R (eds) Climate change in Portugal. Scenarios, impacts and adaptation measures. SIAM Project, Gradiva, 173-219.

Andrade, C., H.O. Pires, R. Taborda, and M.C. Freitas. 2006. Zonas Costeiras. Alterações Climáticas em Portugal Cenários. Impactos e Medidas de Adaptação. Projecto SIAM II. Gradiva. Lisboa, 169208.

Bertin, X., A.B. Fortunato, and A. Oliveira. 2009. Simulating morphodynamics with unstructured grids: description and validation of an operational model for coastal applications. Ocean Modelling, 28, 75-87.

Booij, N., R. Ris, and L. Holthuijsen 1999. A third-generation wave model for coastal regions. 1. Model description and validation. Journal of Geophysical Research, 104(7), 649-666.

Bruneau, N., A.B. Fortunato, G. Dodet, P. Freire, A. Oliveira, and X. Bertin. 2011. Future evolution of a tidal inlet due to changes in wave climate, sea level and lagoon morphology (Óbidos Lagoon, Portugal). Continental Shelf Research, 31, 1915-1930.

Coelho, C.D.B. 2005. Riscos de Exposição de Frentes Urbanas para Diferentes Intervenções de Defesa Costeira. PhD Thesis, Aveiro, Portugal, 404 pp.

Dias, J.M. 2001. Contribution to the Study of the Ria de Aveiro Hydrodynamics. PhD dissertation, University of Aveiro, Portugal, 288 pp.

Dias, J.M., and J.F. Lopes. 2006. Implementation and assessment of hydrodynamic, salt and heat transport models: the case of Ria de Aveiro lagoon (Portugal). Environmental Modelling Software, 21, 1-15.

Dodet, G., X. Bertin, and R. Taborda. 2010. Wave climate variability in the North-East Atlantic Ocean over the last six decades. Ocean Modelling, 31(3-4), 120-131.

Fortunato, A.B., and A. Oliveira. 2004. A modeling system for long-term morphodynamics. Journal of Hydraulic Research, 42(4), 426-434.

Fortunato, A.B., and A. Oliveira. 2007. Improving the stability of a morphodynamic modeling system. Journal of Coastal Research, Special Issue 50, 486-490.

Fortunato, A.B., X. Bertin, and A. Oliveira. 2009. Space and time variability of uncertainty in morphodynamic simulations. Coastal Engineering, 56, 886-894.

IPCC. 2007. Climate Change 2007: Synthesis Report. Contribution of Working Groups I, II and III to the Fourth Assessment Report of the Intergovernmental Panel on Climate Change. Core Writing Team, Pachauri, R.K and Reisinger, A. (ed), IPCC, Geneva, Switzerland, 104 pp.

Larangeiro, S.H.C.D., and F.S.B.F. Oliveira. 2003. Assessment of the longshore sediment transport at Buarcos beach (West coast of Portugal) through different formulations. In: CoastGis'03, Genova

Lopes, C.L., P.A. Silva, J.M. Dias, A. Rocha, A. Picado, S. Plecha, and A.B. Fortunato. 2011. Local sea level change scenarios for the end of the 21st century and potential physical impacts in the lower Ria de Aveiro (Portugal). Continental Shelf Research, 31, 14, 1515-1526.

Marsland, S.J., H. Haak, J.H. Jungclaus, M. Latif, and F. Röske. 2003. The Max Planck Institute global ocean/sea-ice model with orthogonal curvilinear coordinates. Ocean Modelling, 5, 91-127.

Meehl, G.A., C. Covey, T. Delworth, M. Latif, B. McAvaney, J.F.B. Mitchell, R.J. Stouffer, and K.E. Taylor. 2007. The WCRP CMIP3 multi-model dataset: A new era in climate change research. Bulletin of the American Meteorological Society, 88, 1383-1394.

Oliveira, I.M., A.F. Valle, and F. Miranda. 1982. Litoral problems in the portuguese west coast. In Coastal Engineering 1982 Proceedings, Vol. III., 1951-1969.

Plecha, S. 2011. Contribution to the study of the Ria de Aveiro inlet morphodynamics. PhD thesis, Aveiro, Portugal, 163 pp.

Plecha, S., S. Rodrigues, P. Silva, J.M. Dias, A. Oliveira, and A.B. Fortunato. 2007. Trends of bathymetric variations at a tidal inlet. Proceedings of the 5th IAHR Symposium on River, Coastal and Estuarine Morphodynamics, Enschede, The Netherlands, Eds M. Dohmen-Janssen \& S. Hulscher, 19-23.

Plecha, S., P.A. Silva, N. Vaz, X. Bertin, A. Oliveira, A.B. Fortunato, and J.M. Dias. 2010. Sensitivity analysis of a morphodynamic modelling system applied to a coastal lagoon inlet. Ocean Dynamics, 60, 275-284

Plecha, S., P.A. Silva, A. Oliveira, and J.M. Dias. 2012. Establishing the wave climate influence on the morphodynamics of a coastal lagoon inlet. Ocean Dynamics, 62, 799-814.

Ribeiro, N.A., A.B. Fortunato, and A. Rocha. 2012. Efeito das alterações climáticas no regime de agitação marítima no Atlântico Norte e costa Portuguesa, 2as Jornadas de Engenharia Hidrográfica, Instituto Hidrográfico, 163-166. 
Roeckner, E., G. Bäuml, L. Bonaventura, R. Brokopf, M. Esch, M. Giorgetta, S. Hagemann, I. Kirchner, L. Kornblueh, E. Manzini, A. Rhodin, U. Schlese, U. Schulzweida, and A. Tompkins. 2003. The atmospheric general circulation model ECHAM5. Part I: Model description. Max Planck Institute for Meteorology Rep. 349, 127 pp.

Silva, J. and R.W. Duck. 2001. Historical changes of bottom topography and tidal amplitude in the Ria de Aveiro, Portugal - trends for future evolution. Climate Research, 18, 17-24.

Sutherland, J., A.H. Peet, and R.L. Soulsby. 2004. Evaluating the performance of morphological models. Coastal Engineering, 51, 917-938.

Teixeira, S.L.R.B. 1994. Dinâmica Morfosedimentar da Ria de Aveiro Portugal. PhD thesis, Lisbon, Portugal, 396 pp.

Tolman, H.L., B. Balasubramaniyan, L.D. Burroughs, D.V. Chalikov, Y.Y. Chao, H.S. Chen, and V.M. Gerald. 2002. Development and implementation of wind generated ocean surface wave models at NCEP. Weather Forecast, 17, 311-333.

van de Graaff, J., and J. van Overeem. 1979. Evaluation of sediment transport formulae in coastal engineering practice. Coastal Engineering, 3, 1-32.

Zhang, Y., A.M. Baptista and E.P. Myers. 2004. A cross-scale model for 3D baroclinic circulation in estuary-plume-shelf systems: I. Formulation and skill assessment. Continental Shelf Research, 110(10), 1431-1456. 